\title{
High plasma Amyloid $\beta 42$ and P-tau in mild cognitive impairment as risk factors of the disease
} Fereshteh Sedaghat*1,2, Anna Gotzamani-Psarrakou², Eleni Dedousi², Vassiliki Costa1, Vassiliki Tsavdaridou ${ }^{3}$, Athanasios S Dimitriadis ${ }^{4}$ and Stavros J Baloyannis ${ }^{1}$

Address: ${ }^{1}$ First Department of Neurology, AHEPA University Hospital, Thessaloniki, Greece, ${ }^{2}$ Department of Nuclear Medicine, AHEPA University Hospital, Thessaloniki, Greece, ${ }^{3}$ Department of Biochemistry, AHEPA University Hospital, Thessaloniki, Greece and ${ }^{4}$ Department of Radiology, AHEPA University Hospital, Thessaloniki, Greece

* Corresponding author

from International Society on Brain and Behaviour: 3rd International Congress on Brain and Behaviour

Thessaloniki, Greece. 28 November - 2 December 2007

Published: 17 April 2008

Annals of General Psychiatry 2008, 7(SuppI I):SI82 doi:I0.II86/I744-859X-7-SI-SI82

This abstract is available from: http://www.annals-general-psychiatry.com/content/7/SI/SI82

(c) 2008 Sedaghat et al.; licensee BioMed Central Ltd.

\section{Background}

Patients with mild cognitive impairment (MCI) is reported to develop Alzheimer's disease (AD) at the rate of $12 \%$ per year, greatly exceeding the $1 \%$ to $2 \%$ incidence of normal controls. Several studies have shown an increase in plasma $\mathrm{A} \beta 42$ in $\mathrm{MCI}$ compared to normal and $\mathrm{AD}$ patients. The efficiency of $A \beta$ peptides elimination in earlier stages of $\mathrm{AD}$ has proven in animal models. We found no study measuring phospho-tau (p-tau) level in plasma.

\section{Materials and methods}

We measured the plasma level of $A \beta 42$ and p-tau181 in 7 patients with MCI, $29 \mathrm{AD}$ and 16 normal controls who had also underwent brain SPECT imaging.

\section{Results}

Plasma levels of $A \beta 42$ and p-tau were significantly higher in MCI $(57.9 \pm 33.3 \mathrm{pg} / \mathrm{ml})(44.5 \pm 91.5 \mathrm{pg} / \mathrm{ml})$ comparing $\mathrm{AD}(16.3 \pm 15.5 \mathrm{pg} / \mathrm{ml})(3.4 \pm 10.7 \mathrm{pg} / \mathrm{ml})$ and normal group $(12 \pm 7.7 \mathrm{pg} / \mathrm{ml})(00 \mathrm{pg} / \mathrm{ml})(\mathrm{p}<0.000)(\mathrm{p}<0.010)$ respectively.

P-tau was not detectable in normal group but p-tau was detectable in $(57 \%)(4 / 7)$ of patients with MCI and 4 patients with $\mathrm{AD} .3$ patients with $\mathrm{MCI}$ who had high plasma A $\beta 42$ and detectable p-tau too, had shown bilateral
Posterior temporoparietal hypoperfusion and one showed not-characteristic perfusion defects in SPECT.

\section{Conclusions}

Since high plasma A $\beta 42$ and p-tau in our patients with MCI were accompanied by perfusion defect characteristic of $\mathrm{AD}$ which is said to be a sign of the progression of MCI to $\mathrm{AD}$, we suggest the evaluation of plasma $\mathrm{A} \beta 42$ and $\mathrm{p}$ tau as the risk factors of the disease in patients with MCI. 